\title{
Alpha-type-1 Polarized Dendritic Cells
}

National Cancer Institute

\section{Source}

National Cancer Institute. Alpha-type-1 Polarized Dendritic Cells. NCI Thesaurus. Code C64846.

A mature polarized dendritic cell with potent immunostimulating activity. Treating dendritic cells (DCs) with interferon-alpha (IFN-a) and polyinosinic:polycytidylic acid ( $p-1: C)$ in addition to a cytokine cocktail (tumor necrosis factor alpha/Interleukin-1 beta/IFNgamma) produces mature but not exhausted alpha type-1 polarized DCs (alphaDC1) that are capable of: 1) high responsiveness to other lymphoid chemokines, and 2) producing high level of interleukin-12p70 (IL-12p70). Therefore, alphaDC1 has a much more significant capability of inducing helper T cell (CD4+ T-cell) responses in comparison with the "gold standard" DCs. When pulsed with specific tumor associated antigens (TAAs), alphaDC1 is able to induce a potent cytotoxic $T$ lymphocyte $(C T L)$ response against TAAs; as a result it can be used as a cancer vaccine. 